\title{
Properties and durability of alkali-activated ladle slag
}

\author{
Elijah Adesanya ${ }^{1}$, Katja Ohenoja $^{1}$, Paivo Kinnunen ${ }^{1,2}$, and Mirja Illikainen ${ }^{1, *}$ \\ ${ }^{1}$ Faculty of Technology, Fibre and Particle Engineering Unit, PO Box 4300, 90014 University of Oulu, \\ Finland. \\ ${ }^{2}$ Department of Civil and Environmental Engineering, London SW7 2BU, Imperial College London, United \\ Kingdom. \\ * Corresponding Author: Mirja Illikainen Mirja.illikainen@oulu.fi+358405885904
}

\begin{abstract}
This paper examines the durability of alkali activated ladle slag mortars. Ladle slag, currently an under-utilized crystalline metallurgical by-product, is a promising raw material for alkali activation. However, there is no information about the durability of this material. The aim of this study is to investigate the durability of the alkali activated ladle slag mortar and the effect of aggregate content on the properties. The mechanical strength tests were carried out at 7, 28, 56 and 90 days. In addition, the samples were subjected to drying shrinkage, freeze-thaw, and water absorption tests. Furthermore, the reaction products conversion related to the strength properties were also analysed through thermal analysis. Overall, significant strength and durability properties was attained and significantly influenced by the mix design.
\end{abstract}

Keywords: Ladle slag $\bullet$ Durability $\bullet$ Shrinkage $\bullet$ Freeze-thaw resistance $\bullet$ Alkali activated slag

\section{Introduction}

Alkali activated slags (AAS) have been extensively studied in the recent years, fuelled by the promise of low $\mathrm{CO}_{2}$ emissions and energy consumption [1-5]. AAS exhibits desirable properties such as high early age strength [6,7], fire resistance [8], immobilization of heavy metals [9], impermeability and low heat of hydration [6]. However, they also face some challenges such as rapid setting time and drying shrinkage which subsequently results in cracking [10]. The drying shrinkage of AAS is reported to be between 1.6 to 2.1 times more than in Portland cement concretes [11,12]. Drying shrinkage behaviour of AAS have been studied widely particularly with alkali activated ground granulated blast furnace slag (GGBFS) [10,12-17]. It has been found that various parameters could influence the drying shrinkage of AAS. These parameters includes, the type of activator used, curing conditions and shrinkage-reducing admixtures. Collins and Sanjayan [12] in alkali activation of GGBFS reported a lower drying shrinkage when a shrinkage reducing agent was used, however they also reported that it affected the early age strength of the matrix. Aydin and Baradan [15] using GGBFS, reported that silicate-activated slags were found to have higher drying shrinkage than $\mathrm{NaOH}$ activated slags and OPC mortars. But also obtained higher strength, lower water absorption and porosity values compare with $\mathrm{NaOH}$ activated samples and Ordinary Portland cement (OPC) mortar. Additionally, Bakharev et al. [18] in their studies on effect of curing conditions on drying shrinkage of alkali activated GGBFS concrete found that heat treatment was very effective in reducing drying shrinkage of the concrete and also enhanced high early strength. They also reported reduction in strength of the AAS concrete at later ages.

Unlike blast furnace slag (BFS), ladle slag (LS) has not been widely studied as a precursor for alkali activation due to its crystallinity and typically high content of free lime. The crystalline phases commonly observed for LS are dicalcium silicate $\left({ }^{-}-C_{2} S\right)$, mayenite $\left(\mathrm{Ca}_{12} \mathrm{Al}_{14} \mathrm{O}_{33}\right)$, gehlenite $\mathrm{Ca}_{2}\left(\mathrm{Al}(\mathrm{AlSi}) \mathrm{O}_{7}\right)$, and traces of periclase $(\mathrm{MgO})$ [19]. The prospective of using LS in alkali activation has been previously reported [20] attaining a considerable strength of $65 \mathrm{MPa}$ for the paste samples after 28 days. However, in this previous study the designed samples were paste samples and the durability properties including shrinkage, frost resistance and water absorption were not analysed. Therefore investigation into the durability and resistance of alkali activated ladle slag mortar to these aggressive environments is necessary.

In this study, the durability of the alkali activated ladle slag mortar was studied. Various AALS mortar samples were prepared until the maximum sand aggregates content by means of workability was achieved and they 
were analysed for mechanical strength after 7, 28, 56 and 90 days of curing. The durability was also assessed by measuring the drying shrinkage, water absorption, resistance to freeze-thaw and the relationship with aggregates content was determined.

\section{Materials and methods}

\subsection{Materials}

Ladle slag (LS) sourced from SSAB, Finland was used in this study. The chemical composition of the LS was determined by $\mathrm{x}$-ray fluorescence and is presented in Table 1 . Free $\mathrm{CaO}$ for the $\mathrm{LS}$ was measured as $0.0 \%$ using the method refer to in the standard EN 450-1 [21]. The received LS has median particle size $\left(\mathrm{d}_{50}\right)$ of 34 $\mu \mathrm{m}$ and was further ball milled to achieve $\mathrm{d}_{10}, \mathrm{~d}_{50}$ and $\mathrm{d}_{90}$ of $1.32 \mu \mathrm{m}, 8 \mu \mathrm{m}$ and $34.58 \mu \mathrm{m}$ respectively. Analytical grade potassium hydroxide pellets, diatomaceous earth (DE) and sodium silicate solution composed of $26.5 \% \mathrm{SiO}_{2}, 8 \%$ of $\mathrm{Na}_{2} \mathrm{O}$ and $65.5 \% \mathrm{H}_{2} \mathrm{O}$ by mass and a solution modulus $\left(\mathrm{Ms}=\mathrm{SiO}_{2} / \mathrm{Na}_{2} \mathrm{O}\right)$ of 3.5 was used as an alkali activator. For the mortar samples, CEN standard sand conforming to EN 196-1 requirements supplied by Normensand GmbH (Germany) was used.

Table 1. Chemical composition of ladle slag (\% of mass).

\begin{tabular}{ccccccc}
\hline $\mathrm{CaO}$ & $\mathrm{Al}_{2} \mathrm{O}_{3}$ & $\mathrm{SiO}_{2}$ & $\mathrm{MgO}$ & $\mathrm{Fe}_{2} \mathrm{O}_{3}$ & Others & LOI at $950{ }^{\circ} \mathrm{C}$ \\
\hline 46.3 & 28.3 & 8.6 & 7.4 & 5.0 & 4.4 & -1.3 \\
\hline
\end{tabular}

The mineralogy of the slag was determined using a Rigaku SmartLab $9 \mathrm{~kW}$ x-ray diffraction equipment. The analysis employed $\mathrm{Cu} \mathrm{K} \alpha$ radiation $(\mathrm{K} \alpha 1=1.54059 \AA ; \mathrm{K} \alpha 2=154441 \AA ; \mathrm{K} \alpha 1 / \mathrm{K} \alpha 2=0.497)$, at a scan rate of $3 \%$ min between $10^{\circ}$ and $70^{\circ}(2 \theta)$, and $0.02^{\circ}$ step. Phase identification was done using "X'pert HighScore Plus" (PANalytical software). Quantitative XRD was undertaken to determine the amorphous and crystalline content in the slag, analytical grade crystalline Titanium oxide (10 wt.\%) was added to the slag as internal standard. The content was then calculated following an equation proposed by De La Torre et al. [22]. The mineralogical phases and crystallinity content determined are shown in Fig. 1 and in Table 2.
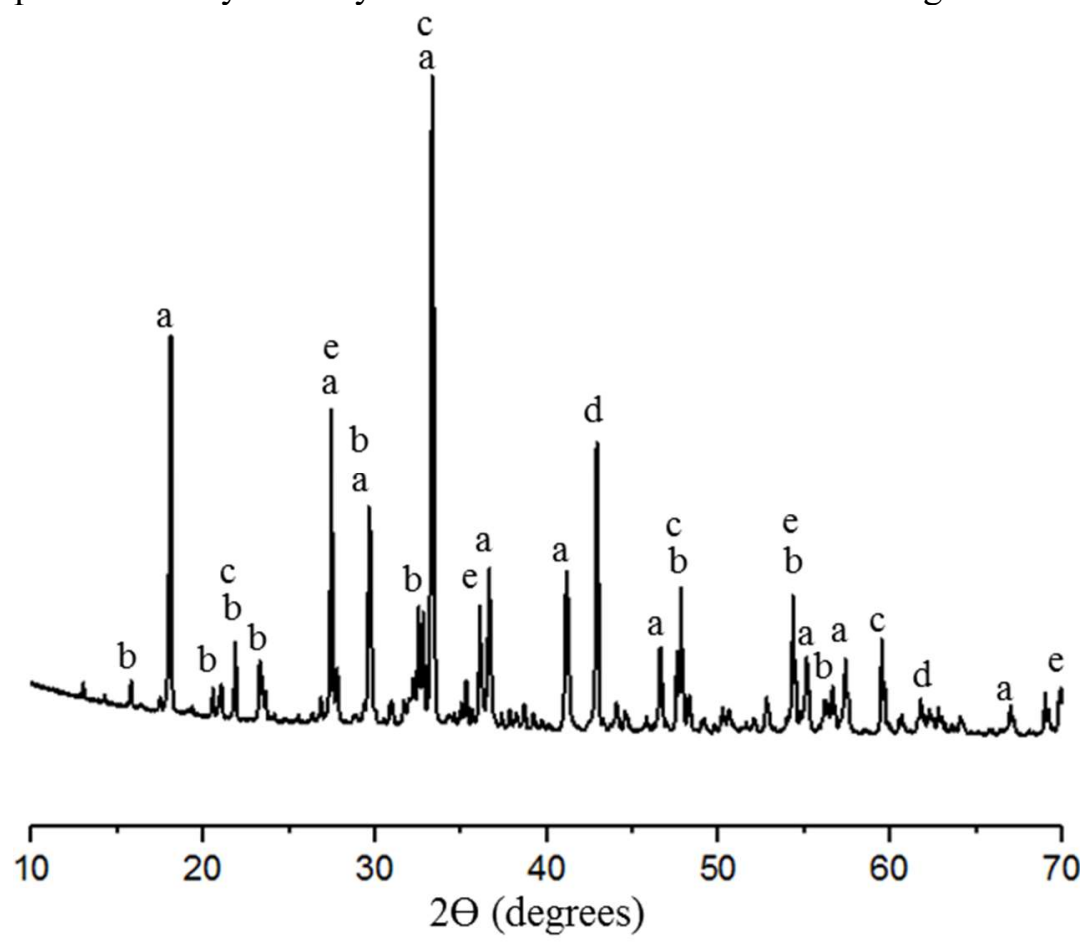

Fig. 1. QXRD pattern of raw ladle slag: $a=$ mayenite $\left(\mathrm{C}_{12} \mathrm{~A}_{7}\right), \mathrm{b}=$ calcio-olivine $\left(\mathrm{\gamma}-\mathrm{Ca}_{2} \mathrm{SiO}_{4}\right), \mathrm{c}=$ tricalcium aluminate $\left(\mathrm{C}_{3} \mathrm{~A}\right), \mathrm{d}=$ periclase $(\mathrm{MgO})$ and $\mathrm{e}=$ Rutile $\left(\mathrm{TiO}_{2}\right)$. 
Table 2. Quantification of the raw slag

\begin{tabular}{ccccl}
\hline $\mathrm{C}_{12} \mathrm{~A}_{7}$ & $\mathrm{\gamma}-\mathrm{Ca}_{2} \mathrm{SiO}_{4}$ & $\mathrm{C}_{3} \mathrm{~A}$ & $\mathrm{MgO}$ & Amorphous \\
\hline 34.6 & 18.2 & 18.7 & 7.96 & 21.3 \\
\hline
\end{tabular}

2

\subsection{Sample preparation}

The activating solution of sodium silicate (Na-Sil), DE and KOH were mixed one day prior to mortar preparation to attain ambient temperature for the solution. The mortar samples were prepared using a modified method based on EN 196-1 [23] using the mix composition presented in Table 3. The water-to-solid (w/s) ratio in all samples was fixed at 0.39 . The water content was taken as the $65.5 \%$ of the sodium silicate weight while the solid was the total dry mass of the slag and the dry mass of the added alkali. It should be noted that increasing the aggregate to slag ratio reduces the workability and promotes setting of the sample due to aggregates wetting, therefore sand to slag ratio of 3:1 was not achievable in this study. Prismatic specimens $(20 \times 20 \times 80 \mathrm{~mm})$ were cast for compressive strength and water absorption measurements. Specimens were demoulded after $24 \mathrm{~h}$ of curing at $60^{\circ} \mathrm{C}$ and placed in a humidity chamber at $90 \%$ relative humidity (RH) and $23{ }^{\circ} \mathrm{C}$ until testing time. The samples for shrinkage measurements were casted in $40 \times 40 \times 160 \mathrm{~mm}$ moulds and cured at $60{ }^{\circ} \mathrm{C}$ for $24 \mathrm{~h}$ and demoulded thereafter. The initial length of shrinkage prisms was measured before placing them in the humidity room at $50 \% \pm 5 \mathrm{RH}$ and $20 \pm 3{ }^{\circ} \mathrm{C}$. The ladle slag paste sample was made similarly as the mortar samples except there is no sand aggregates in its composition.

Table 3. Mix composition of paste and mortar samples.

\begin{tabular}{ccccccc}
\hline Sample name & LS $(\mathrm{g})$ & Na-Sil $(\mathrm{g})$ & KOH $(\mathrm{g})$ & DE $(\mathrm{g})$ & sand $(\mathrm{g})$ & $\mathrm{s} / \mathrm{b}^{*}$ \\
\hline SS0 & 585 & 478 & 20 & 20 & 0 & 0 \\
\hline SS1 & 585 & 478 & 20 & 20 & $757 \pm 5$ & 1.3 \\
\hline SS2 & 585 & 478 & 20 & 20 & $924 \pm 5$ & 1.6 \\
\hline SS3 & 585 & 478 & 20 & 20 & $1350 \pm 5$ & 2.3 \\
\hline
\end{tabular}

*The sand-to-binder $(\mathrm{s} / \mathrm{b})$ ratio was taken as the ratio of the sand content in the mix to the slag.

\subsection{Mortar strength test}

The unconfined compressive strengths for four replicate samples were measured after 7, 28, 56 and 90 days of curing using a Zwick testing machine with a maximum load of $100 \mathrm{kN}$ employing a loading force of $2.4 \mathrm{kN} / \mathrm{s}$. One data point was further than $10 \%$ from the average, and was therefore removed as an outlier (SS0, 7 days).

\subsection{Thermogravimetric Analysis}

To study the reaction products and the conversion processes, thermal analysis was later carried out on samples aged 3, 28 and 90 days of the paste samples using Precisa Gravimetrics AG "prepASH automatic drying and ashing system". The samples were crushed and heated to $1000^{\circ} \mathrm{C}$ at $10^{\circ} \mathrm{C} / \mathrm{min}$ in nitrogen atmosphere.

\subsection{Freeze-thaw (F-T) cycling}

For each mix composition in Table 3, two replicate prism samples with a dimension of $40 \mathrm{x} 40 \mathrm{x} 160 \mathrm{~mm}$ was used for the freeze thaw test modified from ASTM testing method [24]. The test was started at the sample age of 35 days. The mortars were immersed in water, ensuring just half $(20 \mathrm{~mm})$ of the sample being inside water and the other half in air, and then subjected to 60 freeze-thaw (F-T) cycles in a humidity chamber with temperatures ranging from -20 to $+15^{\circ} \mathrm{C}$. Each cycle involves lowering of the temperature of the samples from $+15 \mathrm{C}$ to $-20^{\circ} \mathrm{C}$ in $2 \mathrm{hrs}$ and another $2 \mathrm{hrs}$ to maintain the temperature at $-20{ }^{\circ} \mathrm{C}$, then the temperature is increased from -20 to $+15^{\circ} \mathrm{C}$ for $2 \mathrm{hrs}$ and allowed to thaw for another $2 \mathrm{hrs}$ at $15{ }^{\circ} \mathrm{C}$ (See supplementary data). After 60 cycles, the structural appearance as well as the strength and weight for each sample was analysed. Matest ultrasonic pulse was used to determine pulse velocity before freeze thaw and after 60 cycles of freeze thaw. The relative dynamic modulus of elasticity $\left(R_{d}\right)$ was then calculated using equation $(1)[25,26]$. 


$$
\mathrm{R}_{\mathrm{d}}=\left(V_{n}^{2} / V_{0}^{2}\right) \times 100,
$$

where $V_{n}$ is the ultrasonic pulse velocity after $n$ cycles and $V_{o}$ at 0 cycles.

2.6 Drying shrinkage

Drying shrinkage measurements were carried out on replicate prism samples with a dimension of $40 \mathrm{x} 40 \mathrm{x}$ $160 \mathrm{~mm}$, adapted according to ASTM C596 [27]. The length measurement was carried out at the age of 3, 7, 14, 28 and 90 days. The length change ( $L C$ ) over time was then calculated using equation (2):

$$
\operatorname{LC}(\%)=\frac{L_{i}-L_{x}}{G} \times 100,
$$

Where $L_{i}$ is the initial reading after 24 hours of mixing, $L_{x}$ is the length at each curing age of the specimen and $G$ is the nominal effective length.

\subsection{Water absorption}

The water absorption test was modified and carried out after 28 days age of the samples according to ASTM C646-06 [28]. The samples were dried in the oven at $105^{\circ} \mathrm{C}$ for $24 \mathrm{~h}$ and then weighed $\left(m_{d}\right)$. Samples were then immersed in water and analysed after 3, 7, and 14 days in water to determine the continuous absorption of water into the matrix. At each day the samples were dried with a damp cloth before being weighed $\left(m_{w 3}\right.$, $m_{w 7}$ and $\left.m_{w 14}\right)$. Water absorption $\left(W_{m}\right)$ was reported as in equation (3) as the percentage increase in weight.

$$
\mathrm{W}_{\mathrm{m}}=\frac{m_{w}-m_{d}}{m_{d}} \times 100
$$

\subsection{Scanning electron microscopy}

Backscatter scanning electron microscopy (SEM) analysis was conducted using a Zeiss Ultra Plus microscope fitted with an energy dispersive $\mathrm{x}$-ray spectroscopy (EDS). An accelerating voltage of $15 \mathrm{keV}$ was used to analyse the structural and chemical texture of the polished samples. Before the analysis, the bulk samples were casted with epoxy, then polished with $3 \mu \mathrm{m}, 1 \mu \mathrm{m}$ and $0.25 \mu \mathrm{m}$ diamond paste.

\section{Results and discussion}

\subsection{Strength development is affected by the $\mathrm{s} / \mathrm{b}$ ratio}

All prisms of the alkali activated ladle slag exhibited good performance with at least $55 \mathrm{MPa}$ after 7 days, see Fig. 2. The effect of aggregate content was significant on the compressive strength at 7 and 28 days. Expectedly, the high s/b of 2.30 had the highest early age strength with $76 \mathrm{MPa}$ at 7 days while remarkably, SS0 performed better than SS1 and SS2 at same early age. However, temporary reduction in strength was observed for all samples between 7 and 28 days. This temporary decrease in strength is attributed to conversion of metastable reaction product to a stable one. Similar strength reduction has been reported with calcium aluminate cement with comparable chemical and mineralogical composition as ladle slag [29-31]. Furthermore at 90 days, the strength of all AALS samples are comparable independent of the $\mathrm{s} / \mathrm{b}$ ratio. The rise in strength at 56 and 90 days unlike in hydrated CAC cements is due to the gradual activation of ${ }^{-}-\mathrm{Ca}_{2} \mathrm{SO}_{4}$ and the diffusion of silica ions into the calcium aluminates reaction products. Shi [32] studied the strength development of alkaline activated ${ }_{\gamma}-\mathrm{Ca}_{2} \mathrm{SO}_{4}$, it was reported a significant increment in strength with $21 \mathrm{MPa}$ after 90 days compared to $3 \mathrm{MPa}$ at 3 days. 


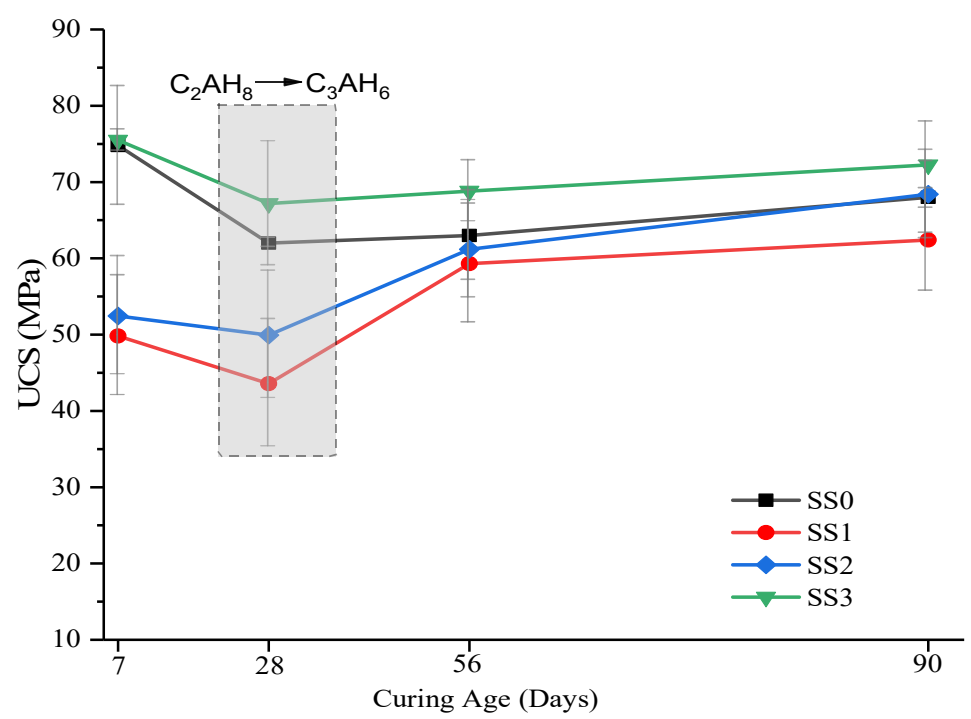

Fig. 2. Unconfined compressive strength of alkali-activated ladle slag samples.

\subsection{Reaction product conversion}

Ladle slag is mineralogically and chemically similar to calcium aluminates cement (Fig. $1 \& 3$ and Tables 12 ), and therefore the hydration reaction can be expected to proceed similarly.

The hydration products from calcium aluminate cement (CAC) are known to convert during the curing period of the hydrated cement when conditions are favourable. This conversion phenomenon has been studied and reported by several authors [29-31,33,34]. The common understanding is that the calcium aluminate hydrate phases that are initially formed in the hydration of the calcium aluminate cement $\left(\mathrm{CAH}_{10}\right.$ and $\left.\mathrm{C}_{2} \mathrm{AH}_{8}\right)$ are thermodynamically unstable and they convert over time to stable hydrates with lower strength and smaller volume, namely $\mathrm{C}_{3} \mathrm{AH}_{6}$ (a form of hydrogarnet) and gibbsite $\left(\mathrm{AH}_{3}\right)$ [29,31]. Ladle slag mineralogy and chemical composition has some similarities with calcium aluminates cement as shown in the ternary diagram in Fig.3.

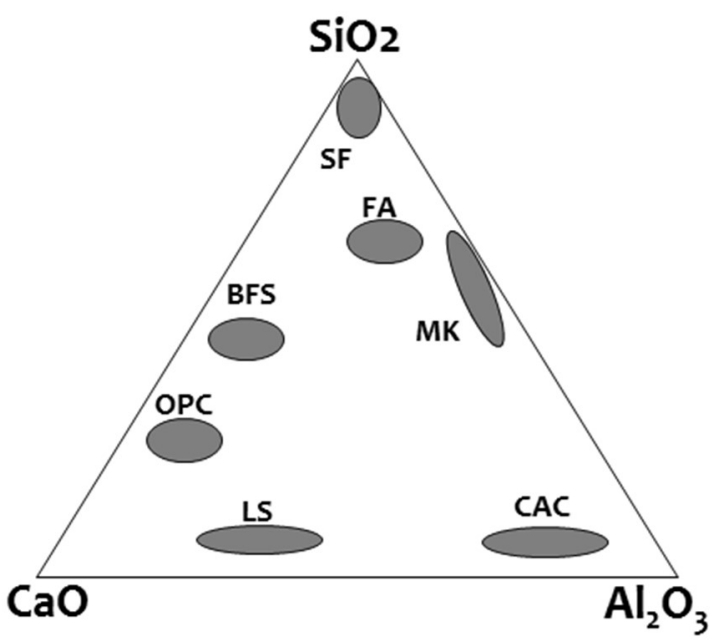

Fig. 3. Ternary diagram of ladle slag and other materials: FA- fly ash, SF - Silica fume, MK - Metakaolin, BFS - Blast furnace slag, LS and CAC.

Ladle slag consist of $35 \% \mathrm{C}_{12} \mathrm{~A}_{7}$ and in cements containing $\mathrm{C}_{12} \mathrm{~A}_{7}$ and alkali, the initial hydration reaction favours metastable $\mathrm{C}_{2} \mathrm{AH}_{8}$ instead of $\mathrm{CAH}_{10}[31,35]$. This initial reaction and subsequent conversion is shown in equations (4-7):

$\mathrm{C}_{12} \mathrm{~A}_{7}+51 \mathrm{H} \rightarrow 6 \mathrm{C}_{2} \mathrm{AH}_{8}+\mathrm{AH}_{3} \quad$ (between 0-7 days) 
In the presence of soluble silica or alkaline activation of $\mathrm{y}^{-} \mathrm{Ca}_{2} \mathrm{SiO}_{4}[32]$, the reaction in equation (5) may take place concurrently.

$\mathrm{C}_{12} \mathrm{~A}_{7}+51 \mathrm{H}+6 \mathrm{~S} \rightarrow 6 \mathrm{C}_{2} \mathrm{ASH}_{8}+\mathrm{AH}_{3} \quad$ (between 0-7 days)

Then the conversion of the metastable hydrate $\left(\mathrm{C}_{2} \mathrm{AH}_{8}\right)$ to $\mathrm{C}_{3} \mathrm{AH}_{6}$ in equation (6) leads to a decrease in solid volume and increased porosity, which leads to strength reduction at 28 days.

$3 \mathrm{C}_{2} \mathrm{AH}_{8} \rightarrow 2 \mathrm{C}_{3} \mathrm{AH}_{6}+\mathrm{AH}_{3}+9 \mathrm{H} \quad$ (after 7-28 days)

The strength is found to increase at 56 and 90 days (Fig. 2), which is consistent with the reaction of unreacted silica (from activator) with $\mathrm{C}_{3} \mathrm{AH}_{6}$ :

$2 \mathrm{C}_{3} \mathrm{AH}_{6}+2 \mathrm{~S} \rightarrow 2 \mathrm{C}_{3} \mathrm{ASH}_{6} \quad$ (after 28 days)

Similar diffusion of silica ions into the calcium aluminate hydrates has previously been observed in studies by Midgeley et al. [36] and Hidalgo et al.[37] on CAC hydration.

\subsection{Thermal analysis (DTG/TGA)}

Thermogravimetric analysis was used to confirm the reaction products conversion mechanism and identification of reaction products (Fig. 4). The as-received LS is indistinctive and shows that only the reaction products contribute to the mass loss of the AALS binder. Weight losses below $100^{\circ} \mathrm{C}$ usually indicates the evaporation of capillary pore water and phases with bound water. At 3 days, the AALS paste weight loss at $50-230^{\circ} \mathrm{C}$ and an overlapped peak at $230-260^{\circ} \mathrm{C}$ could be attributed to the presence of the hydrogarnets (C-A$\mathrm{S}-\mathrm{H}$ and $\left.\mathrm{C}_{2} \mathrm{AH}_{8}\right)$ and the dehydration of alumina gel $\left(\mathrm{AH}_{3}\right)$ [38].

At 28 days, two distinct weight losses were identified at 170 and $560^{\circ} \mathrm{C}$. The first weight loss centred at the range $170^{\circ} \mathrm{C}$ is assigned to the shift of dehydration of primarily C-A-S-H and possibly unconverted $\mathrm{C}_{2} \mathrm{AH}_{8}$. Then a broad unique weight loss was observed at $560^{\circ} \mathrm{C}$ which is attributed to the magnitude of conversion of $\mathrm{C}_{2} \mathrm{AH}_{8}$ to $\mathrm{C}_{3} \mathrm{AH}_{6}$. This offers a noteworthy proof of the conversion process and is in agreement with the strength reduction at 28 days (Fig. 2).

As described by Midgeley and Midgeley [31], alkaline hydrolysis may take place under highly alkaline environment resulting in calcium hydroxide, which in the presence of atmospheric $\mathrm{CO}_{2}$ reacts to form $\mathrm{CaCO}_{3}$ :

$\mathrm{C}_{3} \mathrm{AH}_{6}+2 \mathrm{AH}_{3}$ (alkaline environment) $\rightarrow 3 \mathrm{AH}_{3}+3 \mathrm{CH}$

$\mathrm{CH}+\mathrm{CO}_{2} \rightarrow \mathrm{CaCO}_{3}+\mathrm{H}$

These equations (8) and (9) could prescribe why the $\mathrm{C}_{3} \mathrm{AH}_{6}$ endotherm was not identified at either $300-350{ }^{\circ} \mathrm{C}$ or $450-500^{\circ} \mathrm{C}$ but present in the endotherm range $\left(500-750^{\circ} \mathrm{C}\right)$ for decomposition of carbonates and structural $\mathrm{OH}^{-}$groups.

At 90 days, the weight loss centred at $200^{\circ} \mathrm{C}$ is assigned to mainly C-A-S-H. There is a reduction in the intensity of this peak compared with similar peaks at 3 and 28 days confirming the presence of stable reaction phases and conversion of $\mathrm{C}_{2} \mathrm{AH}_{8}$. Furthermore, the peak assigned to $\mathrm{C}_{3} \mathrm{AH}_{6}$ reduced at 90 days, suggesting the diffusion of reactive silica into the hydrates to form more C-A-S-H according which is consistent with strength gains in Fig. 2 after 28 days. 


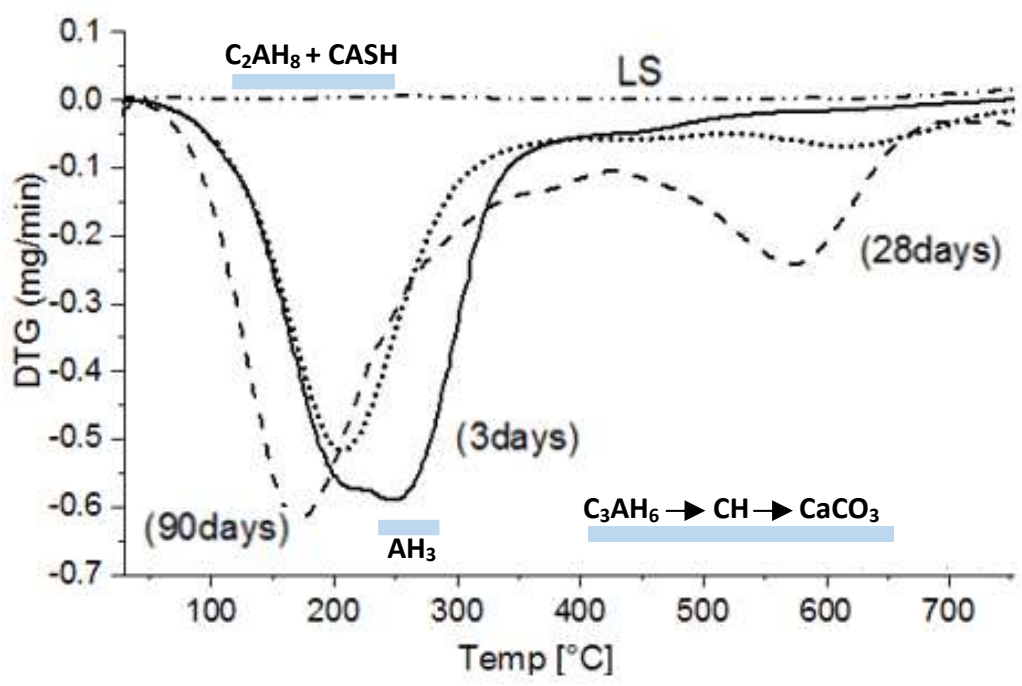

Fig. 4. DTG curves for raw LS and AALS paste.

\subsection{Freeze-thaw durability}

The durability of the AALS samples were analysed by subjecting the partially-submerged specimens to freezethaw cycles. The samples were subjected in total to 60 cycles of extreme freezing and thawing. After 60 cycles, all tested mortar samples showed high resistance against freeze-thaw while the paste samples failed during the experiment (Table 4). The residual compressive strength, weight loss, and relative dynamic modulus elasticity $\left(R_{d}\right)$ were then analysed. For all mortar samples, relative dynamic modulus of elasticity $\left(R_{d}\right)$ after 60 cycles was still above $90 \%$ when compared with the initial $R_{d}$ before freeze-thaw and the weight loss was below $2 \%$. SS1 sample showed the best freeze-thaw resistance with $R_{d}$ of $97 \%$ and weight loss of $1.09 \%$. At the early stages of the cycle, there was marginal deterioration in the appearance of all the samples. However, it should be noted that the SS0 (the paste sample) failed after 35 cycles and therefore the final strength, weight and final modulus was not evaluated. All mixes passed the resistance test except the paste sample, which failed at the end of the test. In terms of strength, both SS2 and SS3 had similar compressive strength after freeze-thaw test compared to the original sample, but SS1 lost $13 \%$ of its original strength.

Table 4: Physical performance of the prepared samples after 60 freeze-thaw cycles.

\begin{tabular}{ccccccc}
\hline \multirow{2}{*}{$\begin{array}{c}\text { Sample } \\
\text { name }\end{array}$} & $\begin{array}{c}\text { Surface } \\
\text { appearance }\end{array}$ & $\begin{array}{c}\text { Control } \\
(\mathrm{MPa})\end{array}$ & $\begin{array}{c}\text { After 60 } \\
\text { cycles (MPa) }\end{array}$ & $\begin{array}{c}\text { Reduction } \\
(\%)\end{array}$ & $\begin{array}{c}\text { Weight } \\
\text { loss } \\
\mathbf{( \% )}\end{array}$ & $\begin{array}{c}\text { Relative dynamic } \\
\text { modulus of } \\
\text { elasticity [\%] }\end{array}$ \\
\hline SS0 & Damaged & $56 \pm 1.1$ & Failed & 100 & - & - \\
SS1 & Good & $55 \pm 1.0$ & $48 \pm 1.7$ & 12.5 & 1.09 & 97 \\
SS2 & Good & $44 \pm 2.4$ & $44 \pm 0.7$ & 0.67 & 1.10 & 92 \\
SS3 & Good & $50 \pm 0.6$ & $49 \pm 1.3$ & 0.96 & 1.71 & 95 \\
\hline
\end{tabular}

The residual appearance of freeze-thaw cycled and non-cycled samples are shown in Fig. 5. Paste sample (SS0) failed with noteworthy damage to the structure after 35 cycles. The failure of SS0 during F-T test can be explained by the water absorption [39]. The water retention is high making it susceptible to frost attack. Indeed it had the highest water absorption (see section 3.6). 

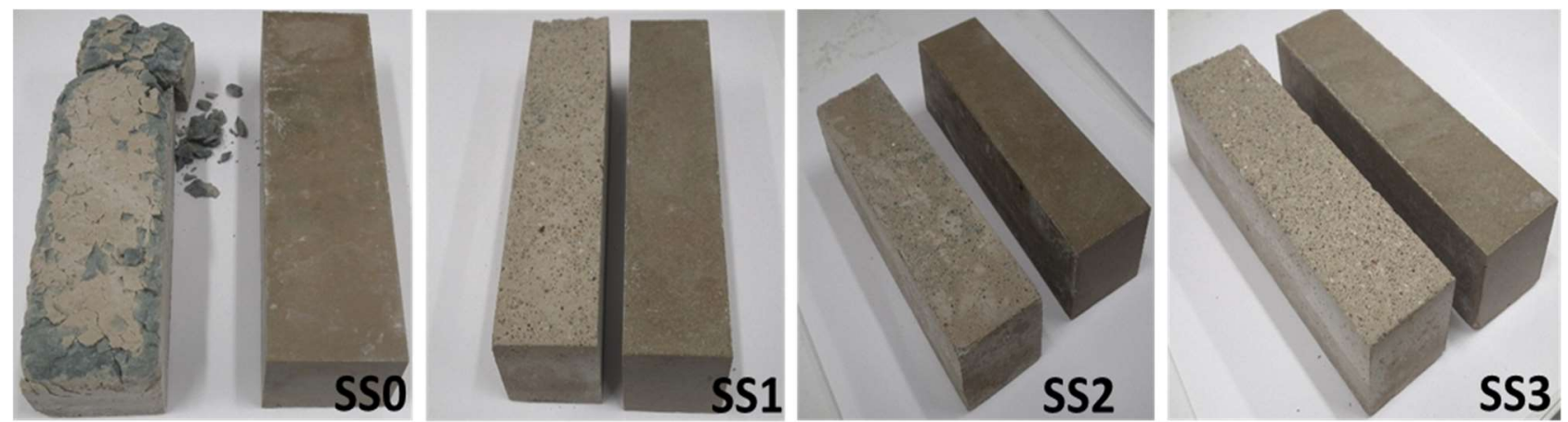

Fig. 5. Residual appearance of freeze-thaw test samples compared to the control.

\subsection{Drying shrinkage}

Drying shrinkage of mortars and concretes is an important parameter that influences their durability and mechanical properties. It can be influenced by the amount of aggregate through dilution since aggregate does not shrink. The addition of aggregates decreased significantly the drying shrinkage of the AALS samples (Fig 6A). The drying shrinkage of the AALS specimens are pronounce at the early ages of the specimens and stabilize after 14 days. The drying shrinkage tendency reduces with increasing amount of aggregates in the mortar as shown in Fig. 6B. SS0 shrinks almost four times more than SS3 and three times more than SS1 after 90 days of measurements. This results is consistent with the findings from earlier studies $[16,40]$. It should be noted that SS0 had visible macro and micro-cracks on it during the testing period (See supplementary data for SEM figures). To further decrease the length change to a minimal value, the rheology of the matrix should be further study in order to incorporate a maximum amount of sand aggregates, this is proposed to enhance the durability of the activated binder mortar.
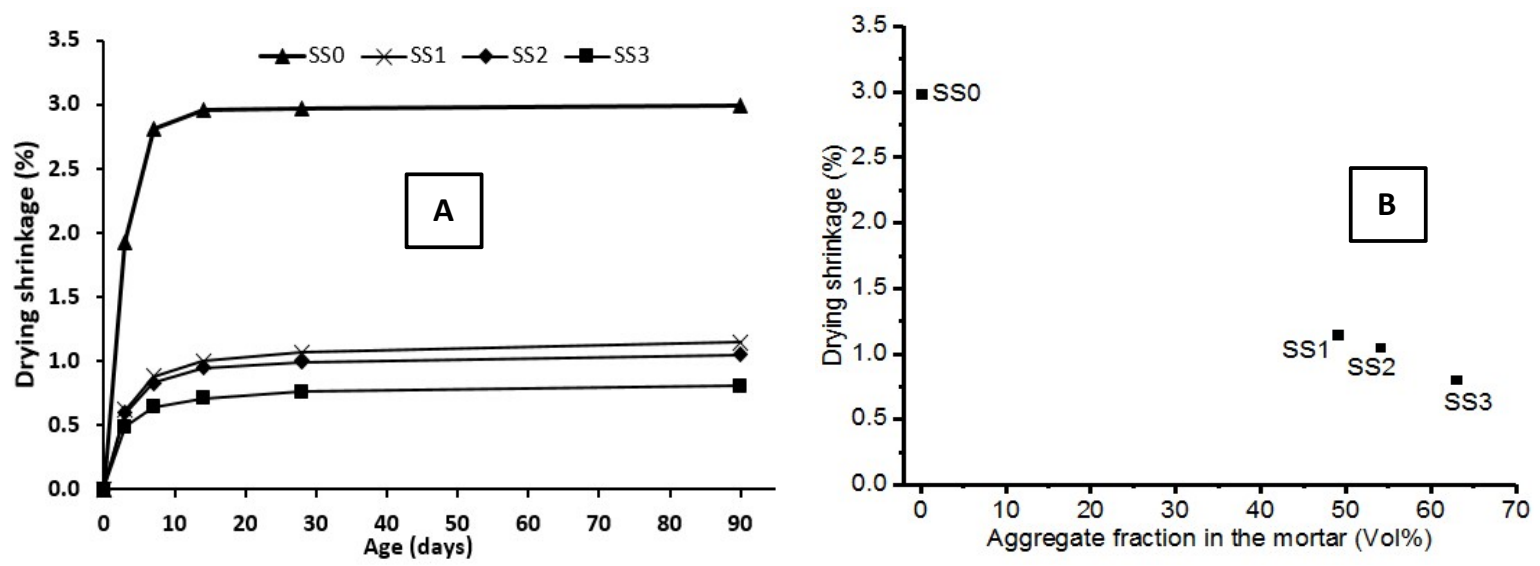

Fig. 6. Drying shrinkage of AALS samples as a function of: (A) time and (B) aggregation fraction.

\subsection{Water absorption}

One of the most important properties of a good concrete is low absorbency to ingress of water. Here we studied the water absorption of the mortars and the paste. The use of aggregates decreased the water absorption capacity (Table 5). The reduced water absorption can be accounted for by the dilution effect as the aggregates increases from SS1 to SS3 (See Fig. 7); because only the binder absorbs water in the matrix. Prolonged exposure to water at 7 and 14 days appears to have no significant influence on the water absorption properties of the mortars. Only exception was SS3 which had an increment in water absorption at 14 days. The result of water ingression into the samples is consistent with the frost resistance results of the samples. 


\begin{tabular}{lcccc}
\hline & SS0 & SS1 & SS2 & SS3 \\
\hline $\mathrm{WA}_{3 \mathrm{~d}}(\%)$ & 15.4 & 10.4 & 9.8 & 7.4 \\
$\mathrm{WA}_{7 \mathrm{~d}}(\%)$ & 15.6 & 10.4 & 9.8 & 7.4 \\
$\mathrm{WA}_{14 \mathrm{~d}}(\%)$ & 15.8 & 10.4 & 9.8 & 7.7 \\
\hline
\end{tabular}

2

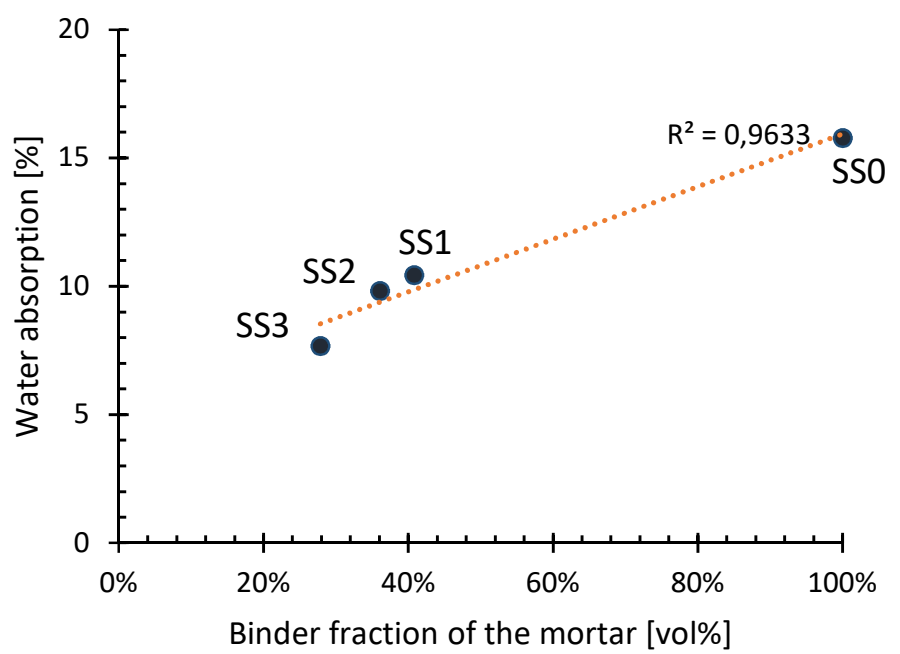

Figure 7. Water absorption after 14 days calculated based on the binder fraction

The binder fraction $\left(\mathrm{b}_{\mathrm{f}}\right)$ was calculated using the equation:

$b_{f}=1 /\left[1+\left(\frac{s}{d_{s}}\right) /\left(\frac{b}{d_{b}}\right)\right]$

where $\mathrm{S}$ is the sand content, $\mathrm{b}$ is the slag content and $d_{s}$ is the density of sand and $d_{b}$ is the slag density.

\section{Conclusions}

Alkali activated ladle slag mortars were found to be durable within the limits of the experiments, despite the relatively low sand-to-binder ratio of 2.30. The durability properties of alkali activated ladle slag mortars were significantly improved with the increasing sand content in the matrix, which is mainly accounted for by the dilution effects of the aggregate. Sample with highest aggregate content had lowest drying shrinkage and water absorption, leading to highest freeze-thaw-resistance. Paste sample was destroyed during the freeze-thaw routine after 35 cycles. Increased aggregate content also affected hydration product conversion, and minimized the resulting drop in compressive strength between 7 and 28 days. Based on the findings, rheology of the matrix should be optimized in order to further increase sand-binder-ratio. All samples contained metastable reaction products to some degree, and therefore also methods to reduce strength loss of the samples due to conversion of metastable reaction products is needed

\section{Acknowledgements}

The research was funded by the European Regional Development Fund (A70189) and the following companies: SSAB Europe Oy, Ekokem Oy, Stora Enso Oy, Pohjolan Voima Oy and Oulun Energia.

\section{Conflict of interest}

The authors declare that they have no conflict of interest. 


\section{References}

[1] T.C. Alex, A.M. Kalinkin, S.K. Nath, B.I. Gurevich, E.V. Kalinkina, V.V. Tyukavkina, S. Kumar, Utilization of zinc slag through geopolymerization: influence of milling atmosphere, Int. J. Miner. Process. 123 (2013) 102-107.

[2] T. Bakharev, J.G. Sanjayan, Y.-B. Cheng, Alkali Activation of Australian Slag Cements, Cem. Concr. Res. 29 (1999) 113-120. doi:10.1016/S0008-8846(98)00170-7.

[3] T. Bakharev, J.G. Sanjayan, Y.-B. Cheng, Effect of admixtures on properties of alkaliactivated slag concrete, Cem. Concr. Res. 30 (2000) 1367-1374. doi:10.1016/S00088846(00)00349-5.

[4] S.A. Bernal, R. San Nicolas, R.J. Myers, R. Mejía de Gutiérrez, F. Puertas, J.S.J. van Deventer, J.L. Provis, $\mathrm{MgO}$ content of slag controls phase evolution and structural changes induced by accelerated carbonation in alkali-activated binders, Cem. Concr. Res. 57 (2014) 33-43. doi:10.1016/j.cemconres.2013.12.003.

[5] S.A. Bernal, J.L. Provis, Durability of Alkali-Activated Materials: Progress and Perspectives, J. Am. Ceram. Soc. 97 (2014) 997-1008. doi:10.1111/jace.12831.

[6] F. Puertas, T. Amat, A. Fernández-Jiménez, T. Vázquez, Mechanical and durable behaviour of alkaline cement mortars reinforced with polypropylene fibres, Cem. Concr. Res. 33 (2003) 2031-2036. doi:10.1016/S0008-8846(03)00222-9.

[7] F. Collins, J.G. Sanjayan, Early Age Strength and Workability of Slag Pastes Activated by $\mathrm{NaOH}$ and Na2CO3, Cem. Concr. Res. 28 (1998) 655-664. doi:10.1016/S00088846(98)00025-8.

[8] T.-W. Cheng, Fire resistant geopolymer produced by waste serpentine cutting, in: Proc. 7th Int. Symp. East Asian Resour. Recycl. Technol. Taiwan, 2003. http://www.ntut.edu.tw/ twcheng/S6R204.pdf (accessed September 12, 2014).

[9] J. Yliniemi, J. Pesonen, M. Tiainen, M. Illikainen, Alkali activation of recovered fuel-biofuel fly ash from fluidised-bed combustion: Stabilisation/solidification of heavy metals, Waste Manag. 43 (2015) 273-282. doi:10.1016/j.wasman.2015.05.019.

[10] F. Collins, J.G. Sanjayan, Microcracking and strength development of alkali activated slag concrete, Cem. Concr. Compos. 23 (2001) 345-352. doi:10.1016/S0958-9465(01)00003-8.

[11] F.G. Collins, J.G. Sanjayan, Workability and mechanical properties of alkali activated slag concrete, Cem. Concr. Res. 29 (1999) 455-458. doi:10.1016/S0008-8846(98)00236-1.

[12] F. Collins, J.G. Sanjayan, Cracking tendency of alkali-activated slag concrete subjected to restrained shrinkage, Cem. Concr. Res. 30 (2000) 791-798. doi:10.1016/S00088846(00)00243-X.

[13] A.R. Sakulich, D.P. Bentz, Mitigation of autogenous shrinkage in alkali activated slag mortars by internal curing, Mater. Struct. 46 (2012) 1355-1367. doi:10.1617/s11527-012-9978-z.

[14] C. Bilim, O. Karahan, C.D. Atiş, S. İlkentapar, Effects of chemical admixtures and curing conditions on some properties of alkali-activated cementless slag mixtures, KSCE J. Civ. Eng. 19 (2015) 733-741. doi:10.1007/s12205-015-0629-0.

[15] S. Aydin, B. Baradan, Effect of activator type and content on properties of alkali-activated slag mortars, Compos. Part B Eng. 57 (2014) 166-172. doi:10.1016/j.compositesb.2013.10.001.

[16] M. Chi, J. Chang, R. Huang, M. Chi, J. Chang, R. Huang, Strength and Drying Shrinkage of Alkali-Activated Slag Paste and Mortar, Strength and Drying Shrinkage of Alkali-Activated Slag Paste and Mortar, Adv. Civ. Eng. Adv. Civ. Eng. 2012, 2012 (2012) e579732. doi:10.1155/2012/579732, 10.1155/2012/579732.

[17] M. Guerrieri, J. Sanjayan, F. Collins, Residual strength properties of sodium silicate alkali activated slag paste exposed to elevated temperatures, Mater. Struct. 43 (2009) 765-773. doi:10.1617/s11527-009-9546-3. 
[18] T. Bakharev, J.G. Sanjayan, Y.-B. Cheng, Effect of elevated temperature curing on properties of alkali-activated slag concrete, Cem. Concr. Res. 29 (1999) 1619-1625. doi:10.1016/S00088846(99)00143-X.

[19] L. Kriskova, Y. Pontikes, F. Zhang, Ö. Cizer, P.T. Jones, K. Van Balen, B. Blanpain, Influence of mechanical and chemical activation on the hydraulic properties of gamma dicalcium silicate, Cem. Concr. Res. 55 (2014) 59-68. doi:10.1016/j.cemconres.2013.10.004.

[20] E. Adesanya, K. Ohenoja, P. Kinnunen, M. Illikainen, Alkali Activation of Ladle Slag from Steel-Making Process, J. Sustain. Metall. (2016) 1-11. doi:10.1007/s40831-016-0089-x.

[21] SFS Online - Betoniin käytettävä lentotuhka. Osa 1: Määritelmät, laatuvattimukset ja vaatimustenmukaisuus, (n.d.). https://online.sfs.fi/fi/index/tuotteet/SFS/CEN/ID2/4/203748.html.stx (accessed January 31, 2017).

[22] A.G. De La Torre, S. Bruque, M. a. G. Aranda, Rietveld quantitative amorphous content analysis, J. Appl. Crystallogr. 34 (2001) 196-202. doi:10.1107/S0021889801002485.

[23] SFS-EN 196-1, Methods of testing cement. Part 1: Determination of strength, 2011.

[24] ASTM C666 / C666M - 15 Standard Test Method for Resistance of Concrete to Rapid Freezing and Thawing, (n.d.). https://www.astm.org/Standards/C666.htm (accessed January 3, 2017).

[25] R. Zaharieva, F. Buyle-Bodin, E. Wirquin, Frost resistance of recycled aggregate concrete, Cem. Concr. Res. 34 (2004) 1927-1932. doi:10.1016/j.cemconres.2004.02.025.

[26] I. Vegas, J. Urreta, M. Frías, R. García, Freeze-thaw resistance of blended cements containing calcined paper sludge, Constr. Build. Mater. 23 (2009) 2862-2868. doi:10.1016/j.conbuildmat.2009.02.034.

[27] ASTM-C596 | Standard Test Method for Drying Shrinkage of Mortar Containing Hydraulic Cement | Document Center, Inc., (n.d.). https://www.documentcenter.com/standards/show/ASTM-C596 (accessed November 4, 2016).

[28] ASTM C642, Standard Test Method for Density, Absorption, and Voids in Hardened Concrete, (n.d.). doi:10.1520/C0642-13.

[29] K. Scrivener, Calcium aluminate cements, in: Adv. Concr. Technol. 1 Const. Mater., Butterworth-Heinemann, Oxford, 2003: p. P2/2-2/19.

[30] I. Odler, Special Inorganic Cements, CRC Press, 2003.

[31] H.G. Midgley, A. Midgley, The conversion of high alumina cement, Mag. Concr. Res. 27 (1975) 59-77. doi:10.1680/macr.1975.27.91.59.

[32] A.J. Majumdar, B. Singh, Properties of some blended high-alumina cements, Cem. Concr. Res. 22 (1992) 1101-1114. doi:10.1016/0008-8846(92)90040-3.

[33] C. Bradbury, P.M. Callaway, D.D. Double, The conversion of high alumina cement/concrete, Mater. Sci. Eng. 23 (1976) 43-53. doi:10.1016/0025-5416(76)90085-9.

[34] S.M. Bushnell-Watson, J.H. Sharp, The application of thermal analysis to the hydration and conversión Reactions of calcium alumínate Cements, Mater. Constr. 42 (1992) 13-32.

[35] C. Shi, Characteristics and cementitious properties of ladle slag fines from steel production, Cem. Concr. Res. 32 (2002) 459-462. doi:10.1016/S0008-8846(01)00707-4.

[36] H.G. Midgley, P. Bhaskara Rao, Formation of stratlingite, $2 \mathrm{CaO} . \mathrm{SiO} 2 . \mathrm{A1} 2 \mathrm{O} 3.8 \mathrm{H} 2 \mathrm{O}$, in relation to the hydration of high alumina cement, Cem. Concr. Res. 8 (1978) 169-172. doi:10.1016/0008-8846(78)90005-4.

[37] A. Hidalgo, J.L. García, M.C. Alonso, L. Fernández, C. Andrade, Microstructure development in mixes of calcium aluminate cement with silica fume or fly ash, J. Therm. Anal. Calorim. 96 (2009) 335-345. doi:10.1007/s10973-007-8439-3.

[38] N.C. Collier, Transition and decomposition temperatures of cement phases - A collection of thermal analysis data, Ceram. - Silik. (2016) 1-10. doi:10.13168/cs.2016.0050. 
[39] B.B. Sabir, Mechanical properties and frost resistance of silica fume concrete, Cem. Concr. Compos. 19 (1997) 285-294. doi:10.1016/S0958-9465(97)00020-6.

3 [40] Z. Li, P.R. Rangaraju, Effect of sand content on properties of self-consolidating, highperformance cementitious mortar, Transp. Res. Rec. 2508 (2015) 84-92. doi:10.3141/2508-11. 